\title{
XXVI.
}

Aus dem pathologischen Institut der Universität Greifswald. (Professor Dr. P. Grawitz.)

\section{Vier seltene Fälle von abdominalen Cysten.}

Von

Dr. M. Penkert,

Assistent am Institnt.

Die Literatur enthält eine grosse Anzahl von cystischen Tumoren, welche der Chirurg kennen, über deren Lage und Ursprung er sich bei der Operation Rechenschaft geben muss. Relativ leicht und sicher lassen sich viele Echinokokkenblasen, manche Pankreascysten, sowie Blasengeschwülste des Mesenteriums und Kystome der Eierstöcke beurtheilen, selbst wenn der Bauchsehnitt nur klein und der Tumor durch einige Verwachsungen fixirt oder verdeckt wird. Im Gegensatz dazu giebt es aber Cysten, welche sogar nach völliger Exstirpation ohne mikroskopisebe Untersuchung noch nicht sicher bestimmt werden können, und solche, welche auch bei der Section technische Schwierigkeiten bieten und erst eingehende diagnostische Bearbeitung erfordern.

Von dieser Gruppe will ich vier Fälle mittheilen, mit der Absicht, auch diese seltenen Fälle der Diagnose intra vitam zugänglicher zu machen.

I. Intraabdominales Haematolymphangioma mixtum.

Einem Kinde wurde ein grosses Lymphangiom exstirpirt. Es starb. Die Section ergab einen unerwarteten und in der Literatur bisher noch nicht beschriebenen Befund.

Krankengeschichte.

Ernst S., 2 Jahre alt, hat seit seiner Geburt eine Geschwulst in der rechten Seite, welche seit ungefähr fünf Wochen sich ständig vergrösserte. Patient musste seit dieser Zeit zu Bett liegen, da gleichzeitig auch eine Magendarmerkrankung auftrat, die den Ernährungszustand ziemlich er- 
heblich beeinträchtigte. Aufnahme in die Kgl. Chirurgische Universitätsklinik zu Greifowald am 10. Mai 1901.

Der Knabe ist schwächlich gebaut, anämisch. In der rechten Seite befindet sich eine weiche Geschwnlst, welche nach oben bis an die neunte Rippe, unten bis uber die Spina anterior superior ossis ilei, hinten bis an die Wirbelsänle und vorn bis an die Medianlinie reicht. An einzelnen Stellen ist die Haut uber der Geschwulst blauroth verfärbt. Die Geschwulst ist leicht compressibel und zeigt deutlich lappigen Bau.

Am 14. Mai 1901 wurde zur Operation in Chloroformnarkose unter streng aseptischen Cautelen geschritten. Die Geschwulst wird umschnitten, die Haut theilweise mitgenommen. Hierbei entleert sich iberaus reichlich Blut und Lymphflussigkeit; z. Th. wird die Neubildung bis anf die Fascie exstirpirt. Plötzlich tritt ein Chloroformzufall ein, die Athmung setzt aus. Provisorisch wird die Wunde geschlossen. Verband. Zwei Stunden lang fortgesetzte kunstliche Athmung bleibt ohne Erfolg. Exitus.

\section{Pathologisch-anatomischer Befund des operativ ent- fernten Tumors.}

Die exstirpirte Geschwulstmasse misst 12:6:4 cm. Das mitgenommene 'spindlig ovale Hautstïck ist blauröthlich gefärbt. In dem darunter liegenden Unterhautbinde- und Fettgewebe siebt man kleinere und grössere Hohlräume bis zur Grösse einer Walnuss. Letztere sind besonders in den tiefliegenden Abschnitten zu finden, wo sie vielfach mit einander communiciren. Sie bilden Hohlräume mit derben fibrösen Wandungen, zwischen ihnen spannen sich dünnere und dickere Septen, säulenartig wie in einem Gewölbe aufgestellte Pfeiler. Das Ganze stellt ein schwammiges Gewebe vor, von deutlich cavernösem Bau. Aus gelbem Fett- und derbem Bindegewebe wird das Gerüst gebildet. Die Hohlräume sind an der Wundfläche ohne Inhalt, nur vereinzelt kann man in ihnen Blutgerinnsel erkennen.

\section{Sectionsbefund.}

Schwächlicher Knabe mit leidlich entwickelter Musculatur und mässigem Fettpolster, anämisch. Farbe der allgemeinen Körperhaut blassgrauweiss. In der rechten Seite zieht in der Höhe der 11. Rippe beginnend eine frische Operationswunde mit vollkommen reactionslosen Rändern von der Wirbelsäule nach vorn und unten zur Spina anterior superior in einer Länge von $22 \mathrm{~cm}$, die durch einige Nähte geschlossen ist. Sie fubrt in einen grossen Sack, aus dem ein nmfangreiches „Lymphangiocavernom" entfernt ist. Bei der Eröffnung der Bauchhöhle sieht man am Lig. teres hepatis pendelartig anfgehängt einen hahnereigrossen Tumor, der fluctuirt und aus bis taubeneigrossen Blasen besteht, gefullt mit hellgelber klarer Flüssigkeit. Derselbe zeigt Fortsetzungen auf der rechten Seite der Linea alba, wo sich jedoch z. Th. blauroth gefärbte kleinere, z. Th. mit hellgelber Flüssigkeit gefullte 
Blasen finden, die unter dem Peritoneum sitzend sich in das subperitoneale Fettgewebe bis fast dicht unter die Cutis fortsetzen. Ferner findet sich ein taubeneigrosser blasiger Tumor in der Gegend des Pankreaskopfes, zwischen diesem und dem oberen horizontalen Aste des Duodenum. Das spinnewebendunne Netz uberlagerte die mässig aufgetriebenen Darmschlingen mit ihrer zarten grauweissen Serosa. Peritoneum spiegelnd glatt und glänzend, nirgends verdickt. Zwerchfellstand rechts in Höhe des unteren Randes der 4., links des oberen Randes der 5. Rippe. In der Bauchhühle keine freie Flüssigkeitsansammlung.

Nach Herausnahme des Brustbeins liegt die Thymus in einer Ausdehnung von $4 \mathrm{~cm}$ Länge, $2 \mathrm{~cm}$ Breite vor. Im Herzbeutel keine vermehrte Flüssigkeit. Das Herz entspricht der Grösse der Fanst der Leiche, geringe Fettträubchen auf beiden Ventrikeln unter dem spiegelnd glatten, glänzenden, zarten und grauweisslichen Pericard. Musculatur blassrosa, straff, contrahirt, misst im rechten Ventrikel 0,3 , im linken $0,7 \mathrm{~cm}$. Ostium aortae $1,4 \mathrm{~cm}$ breit, linker Ventrikel 2,5 cm lang. Emdocard und Klappen zart.

Lungen hellroth, nirgends verwachsen, mit glatter Pleura, auf dem Durchschnitt überall lufthaltiges, hellrothes Gewebe. Bronchien, Trachea und Kehlkopf normal. Im Nasenrachenraum umfangreiche adenoide Wucherungen, die auch nach dem Keblkopf zu sich ausbreiten. Tonsillen beiderseits bypertrophisch.

Die Milz misst 7:4:2 cm. Oberfläche glatt, blauroth, Consistenz ziemlich derb, auf dem Durchschnitt treten in der graublaurothen Grundfarbe die Follikel deutlich hervor.

Die Nierenoberfläche ist beiderseits glatt, blassrosa, Rindensubstanz misst $0,5 \mathrm{~cm}$, graugelblichrosa, transparent, in der blassrothen Marksubstanz keine Veränderungen. Nierenbecken nicht erweitert, mit grauweisslicher Schleimhant. Maasse der linken Niere $7: 4: 2 \mathrm{~cm}$, der rechten $7,2: 4: 2 \mathrm{~cm}$. Im Rectum und in der Blase nichts Pathologisches. Der ziemlich straff contrahirte Magen leer, Schleimhaut grauröthlich, stark gefaltet, im Duodenum gelblichbräunliche Schleimhaut. Papilla duodenalis durchgängig. Die Mesenterialdrüsen sind allenthalben bis zu Bohnengrösse geschwollen, grauweiss, auf dem Durchschnitt glasiggrauweiss, von derber Consistenz, besonders dicht am Mesenterialansatz in reichlicher Anzahl. Im Ileum bis zur Valvula Banhini sind therall in grosser Ausdehnung die Solitärfollikel und Peyer'schen Haufen geschwollen, in letzteren deutlich erkennbar die einzelnen Lymphknötchen. Der Darminhalt schleimig weisslich. Die Leber misst 18:9:5 cm. Blutgehalt gering, leichte Fettinfiltration.

Nach Herausnahme sämmtlicher Organe findet sich rechts neben der Aorta subpleural gelegen dicht unterhalb des Lungenhilus ein Tumor von uber Taubeneigrösse, der sich aus einzelnen Bläschen mit hellgelbem oder dunkelrothem Inhalt gefullt zusammensetzt.

Die Aorta und Vena cava superior und inferior lassen nichts Auffallendes erkennen. Der Ductus thoracicus lässt sich ohne irgendwelche pathologischen Veränderungen bis zu seiner Mundung verfolgen. 


\section{Mikroskopischer Befund.}

a. Hauttumor. Unter der an sich normalen Cutis liegt ein verhältnissmässig zellarmes Fettgewebe. Darin verlaufen in ganz geringer Anzahl kleinste Blutgefässe, an deren Wandung Kernvermehrung sichtbar ist, und eine Anzahl kleiner Lymphräume mit dünner bindegewebiger Wand umkleidet. Hieran schliesst sich ein von massenhaften Räumen unterbrochenes zellarmes Binde- und Fettgewebe, das jedoch stellenweise mit stärkerem Kernreichthum ausgestattet ist. Darunter liegen dann die makroskopisch sichtbaren bis hasel- und fast walnussgrossen Lymphräume. Die Form der Höhlen varïrt sehr. Stark ausgezackte Lymphräume wechseln ab mit mehr rundlichen oder länglichen Bluträumen. Ihre Wandungen bestehen aus derbem Bindegewebe in stärkerer oder schwächerer Schicht z. Th. mit glatten Muskelfasern. Durchweg ist die Innenwand von einer continuirlichen Endothelschicht gebildet. Die Bluträume sind von relativ reichlicherem elastischen Gewebe umgeben als die zur Hälfte mit Blut, zur Hälfte mit Lymphe gefüllten Lymphräume. Daneben existiren auch reine Lymphräume, in deren Inneres sich vielfach Bindegewebszapfen vorstülpen.

Der eben erhobene Befund stammt aus Schnitten, die der Mitte des excidirten grossen IIautstücks entnommen sind. In den Randparticen dieses Geschwulsttheiles waren die Räume fast durchweg nur von Blut erfüllt, eine Erscheinung, die auf die Operation zurückzufïhren ist. Im Allgemeinen kann man die Beobachtung machen, dass die Lymphräume den perivasculären Rüumen der Blutgefässe entsprechen, und dass öfter Blut- und Lymphräume hart aneinander stossen, besonders in dem stark zerklüfteten Gebict. Hier wird auch das Fettgewebe wieder umfangreicher und zeigt starke Vermehrung seiner Kerne, Neubildung von Fettträubchen und zarten Lymphgefässen.

Es folgen dann die Rückenmuskeln mit ibrer Fascie. Sie besteht aus derbem faserigen Bindegewebe mit reichlichen Kernen und ganz verschwindend wenigen, mit reiner Lymphe gefüllten Räumen von kleinerem Umfange, ferner liegt hier älteres Blutpigment, und es sind auch Spuren frischer Blutungen vorhanden. In den tieferen Schichten der Fascie tauchen dann wieder grössere Lymphräume auf, deren Inhalt klare Lymphe mit wenigen farblosen und rothen Blutkörperchen ist.

Ein complicirtes Bild bieten nunmehr die Muskelschichten, die bei der Exstirpation mit entfernt sind. Sie liegen gewissermaassen eingebettet in Fettgewebe, welches sich vollkommen unregelmässig 
zwischen sie drängt. Hierin treten vereinzelte kleine Lymphräume auf, umgeben von einem zarten Bindegewebe, dem als Auskleidung eine Schicht zarter Endothelien anhaftet. Das Fettgewebe ist zellenreicher als unter der Haut. Kleinere Gefässe durchziehen es und verlaufen dann in Schlängelungen in die Musculatur. Sie sind in ihrem Verlaufe umgeben von gleichfalls in das Muskelgewebe sich schlängelnden kleinen perivasculären Lymphräumen mit einer Endothellage und zarter bindegewebiger Wand ohne elastische Fasern. Zuweilen erhält man den Eindruck, als ob Hämangiombildung vorliegt, zumal sich auch kleinere geschlängelte Gefässe mit stärkerer Wandung und geringen elastischen Fasern vorfinden. Der Inhalt der Räume besteht aus reiner Lymphe mit verschwindend wenig farblosen Blutkörperchen, aus Lymphe mit zahlreichen farblosen und rothen, aus rothen Blutkörperchen.

Inmitten der Musculatur, wenn auch in geringerer Ausbreitung der gleiche Befund. Eine Vermehrung der Muskelkerne ist nicht zu bemerken. Die Muskeln zeigen deutliche Längs- und Querstreifung und liegen überall dem Sarkolemm eng an, sodass ich eine Zwischenschicht zwischen beiden nirgends habe finden können, eine Schicht, die aus Lymphe bestehen und beide auseinanderdrängen könnte (wie Wegener annimmt). Directe Degenerationsercheinungen bieten die Muskeln nicht dar, auch nicht in Präparaten, die nach der W eigertschen Nervenfärbung, (wie sie Ritschl angegeben) behandelt worden sind. An den hier vorzufindenden Nerven keine Veränderungen.

b. In den Tumormassen am Lungenhilus zeigt das Fettgewebe einen starken Kern- und Blutgefässreichthum. Es ist an verschiedenen Stellen von massenhaften runden Zellen durchsetzt, die theils in grösserer, theils in geringerer Anzahl zwischen den einzelnen Fettzellen liegen, dabei eine intensive Färbung bei den verschiedensten Färbemethoden annehmen. Besonders zahlreich sind sie in der Nähe der grösseren Gefässe und ziehen entlang den von diesen ausgehenden Bindegewebssepten. Das Fettgewebe zeigt vielfach die normale Grösse der Fettzellen, hin und wieder sieht man aber auch zahlreiche neugebildete junge Fettträubchen, die sich durch besonderen Kernreichthum auszeichnen. Von dem Endothel der hier durchziehenden kleinsten Blutgefässe aus scheint eine Endothelwucherung stattzufinden, die sich nach dem Fettgewebe hin erstreckt und gleichsam die angrenzenden Fettzellen auseinander drängt. Gleichzeitig betheiligt sich auch das Fettgewebe an diesem Proliferationsprocess. Zwischen dem Endothel des Gefässchens und den angrenzenden proliferirten Zellen ist zuweilen ein kleiner Spalt sichtbar, gefüllt mit einer homogenen lymphatischen 
Flüssigkeit, in der dann vereinzelt farblose Blutkörperchen und zerstreut liegend auch Endothelien zu finden sind. Die der Wand der Spalten näherliegenden Endothelien ordnen sich, sodass die Lymphräume dann von einem einschichtigen Endothel begrenzt werden, das direct dem Fettgewebe anliegt. Indem nun dieser Wucherungsprocess theils den Gefässwandungen, theils den bindegewebigen dünnen Septen entlang geht, und sich Lymphräume bilden, kommt ein sehr zerkltiftetes Bild zu Stande. Zwischen den einzelnen Räumen ziehen Septen - an ihnen kann man vielfach deutlich eine Parallelstellung der Kerne des Fettgewebes sehen - durch das letztere, gewissermaassen eine Verbindung zwischen ihnen herstellend. So kommt es denn, dass beim Fortsehreiten obigen Proliferationsprocesses mehrere Lymphräume confluiren und aus einzelnen kleineren Räumen ein grösserer mit vollkommenem Endothelbelag wird. Dabei tritt successive eine Vermebrung der Wandungselemente ein. Man sieht, wie in der Umgebung das Fettgewebe kernreicher ist und in kernreicheres Bindegewebe übergeht, das dann in dickerer oder dünnerer Schicht an dem Endothel lagert. Wie in dem Hauttumor, so wölbt sich auch hier das umgebende Bindegewebe manchmal halbkugelförmig und zapfenartig in das Lumen der Räume vor und zeigt zum Theil radiäre Streifung (wucherndes Bindegewebe). In den grösseren Hohlräumen finden sich verschiedentlich massenhafte weisse Blutkörperchen, die mit besonderer Häufigkeit in den sich gegen das umgebende Fettgewebe vorschiebenden gröberen und feineren Fortsätzen der Lymphräume liegen und so auf Querschnitten das Aussehen kleiner Lymphfollikel bieten, vielleicht fälschlicher Weise auch vielfach als solche angesehen sind.

Einen Gegensatz zu den mit einer regelmässigen Endothelschicht ausgekleideten Hohlräumen bilden Lucken im Fettgewebe, gewöhnlich zwischen dem adventitiellen Bindegewebe der Gefässe und ersterem, wo eine ziemlich derbe Bindegewebsschicht mit einzelnen glatten Muskelfasern zuweilen mit ähnlichen prominirenden Wülsten, wie oben erwähnt, die Abgrenzung auf der einen Seite bildet, auf der anderen Seite eine winzige Bindegewebsschicht oder reines Fettgewebe, wo aber nur vereinzelt ein Endothelbelag (?) zu constatiren ist, während ganze Strecken der Innenwand nur aus reinem Bindeoder Fettgewebe bestehen. Die Fettträubchen stossen stellenweise unvermittelt an den mit Lymphe und ihren. Bestandtheilen erfüllten Raum. (Ich kann mich nicht entschliessen, diese Befunde als Stauungserscheinungen aufzufassen, vielleicht lässt sich annehmen, dass hier ein leichtes Oedem vorliegt - möglich in Folge einer Läsion 
bei der Operation entstanden, oder durch geringe Zerrung bei der Herausnahme der Geschwulst post mortem?)

Aehnlich den von Wegne $r$ beschriebenen Lymphthromben kann man gelegentlich sehen, wie die homogene Lymphe von den Wandungen der Lymphräume abgehoben ist.

Dies tritt in Erscheinung in Form kleiner rundlicher Vacuolen. Zum Theil sind diese auch mehr central in der ausfüllenden Lymphmasse gelegen, hier von rundlicher, oder ovaler, auch spindliger Gestalt. Conglomerate rother Blutkörperchen sind in dem Inhalt mancher Räume zu bemerken, die vielfach im Centrum liegen, ganz oder theilweise umgeben von einer homogenen Lymphmasse oder auch umgekehrt peripherwärts und so ihrerseits die Lymphmasse einkleidend.

Wie oben bei Beschreibung der mitexstirpirten Musculatur erwähnt, liegen ferner im Fettgewebe auch hier Abschnitte, in denen massenhafte Blutgefässe mit dünnerer und dickerer Wandung einen Hauptbestandtheil bilden. Meist mit starker Schlängelung in grösseren Complexen ordnen sie sich vielfach um ein oder zwei grössere Blutgefässe (Arterie und Vene), eine dem Angioma cavernosum ähnliche Erscheinung. Ihre Wandungen werden gebildet von mehr oder weniger stark entwickelten Lagen glatter Muskelfasern und Bindegewebe. Die grösseren Arterien und Venen, in deren Nachbarschaft die stark geschlängelten dünnwandigen Gefässe liegen, zeigen gewöhnlich keinen Inhalt mehr und sind grösstentheils collabirt. Auch in diesem Gebiet wieder die reichlichen grösseren und kleineren perivasculären Lymphräume.

Wie schon oben erwähnt, besteht die Wandung der Lymphräume aus einem zarten Bindegewebe, in das vereinzelt glatte Muskelfas ern eingestreut sind, während die der massenhaften kleineren geschlängelten Gefässe aus verhältnissmässig reichlichen glatten Muskelfasern zusammengesetzt ist.

Ein wesentlicher Unterschied zeigt sich nun auch in dem Verhalten der elastischen Fasern. Was diese betrifft, so finden wir bei den Lymphräumen kleinster Ausdehnung nichts davon, während sich allmählich mit dem Dickerwerden der Wand auch dergleichen Elemente einstellen, wenn auch nur in zartester Weise. Anders die in der Hauptsache nur mit Blut angefüllten Räume; sie enthaltengleichviel ob kleineren oder grösseren Kalibers - durchweg zartere oder gröbere elastische Fasernetze, die auch weiter in die Umgebung der starrwandigen, verdickten grossen Arterien- und Venenrohre zu verfolgen sind. 
Das Netz der elastischen Fasern in den diesem Gebiete angehörenden Hauptgefässen ist ein ganz gewaltiges im Verbältniss zu allen eben dargelegten Befunden an den neugebildeten Lymph- und Bluträumen, besonders ist die Elastica interna vielfach colossal entwickelt.

Wirklichen Lymphfollikeln ähnliche Gebilde sind vereinzelt zu finden mit gleichen Zellen, wie sie normalerweise in den Lymphdrüsen vorliegen. Diese Zellhaufen im Fettgewebe sind umgeben von einer zarten Bindegewebskapsel, im Innern mit Keimcentren und Blutgefässchen, so dass wir wohl normale kleinere Lymphdrüsen vor uns baben, die m. E. ohne Bedeutung für den ganzen Process der Neubildung sind und unabhängig von demselben normalerweise sich finden. Auffallend ist in ihrer Umgebung der Reichthum an in loco gewucherten Bindegewebszellen und Endothelien der kleinen hier verlaufenden Gefässchen und an intensiv gefärbten, farblosen Blutkörperchen, die zwischen die Maschen des Fettgewebes zerstreut wohl ausgewandert sind.

c) Die Geschwulstmassen in der Bauchhöhle bieten im Allgemeinen gleiche mikroskopische Bilder wie die am Lungenhilus. Etwas abweichend stellt sich nur das am Lig. teres hepatis bängende pendelartige Gebilde, das dünne bindegewebige Wandungen zeigt und im Grossen und Ganzen bei seiner Entwickelung bis zu Hühnereigrösse das Aussehen des von W egener als Lymphangioma cysticum bezeichneten Tumors darbietet. Die Wand ist sehr arm an elastischen Fasern mit einer continuirlichen Endothelschicht bekleidet. Die Ausdehnung bis zu diesem Volumen braucht nicht Wunder zu nehmen, da der Vergrösserung durch die leicht zur Seite zu drängenden Darmschlingen keine schwer zu überwindenden Schranken gesetzt sind, zumal die darin enthaltene Lymphflüssigkeit auch das Bestreben hat, dem Gesetz der Schwere folgend, den Tumor nach unten dilatirend zu vergrössern. Eine länger dauernde Stauung liegt hier unbedingt vor, da eine Abflussmöglichkeit in Folge der tiefen Lage weniger geboten ist. Das Ausbleiben der dickeren Wandung erklärt sich auch aus dem eben Gesagten.

Ganz besonders merkwürdig in den Tumormassen ist der Inhalt der einzelnen Lym phräume, auf den näher einzugehen mir nicht unwichtig scheint.

Auffallend ist an zahlreichen Stellen, dass die grösseren oder auch zum Theil kleineren Hohlräume mit Lymphflüssigkeit und Blut, auch nur mit Blut angefüllt sind. Im Allgemeinen ist die Anzahl der venösen Gefässe eine recht reichliche, in manchen Gebieten liegt sogar eine förmliche Haemangioma cavernosum-Bildung vor, in deren Um- 
gebung die Zahl der Lymphräume eine ausserordentlich grosse ist. Vielfach findet sich eine enge Aneinanderlagerung der venösen und lymphatischen Räume. Einige Male konnte ich constatiren, dass nur eine ganz schmale Brïcke .zwischen einem weiten Lymphraum und einer Vene vorhanden war, die aus einer parallel verlaufenden Lage von Endothelien bestand, zwischen denen ein ganz zartes Bindegewebe sich ausspannte.

Wie ich schon mehrfach erwähnte, waren in den inneren Geschwulstmassen einige Hohlräume mit Lymphe angefüllt, die man als thrombosirt hätte bezeichnen können. Hierbei war eigenthümlicher Weise der gleiche Befund zu erheben, wie ihn Wegner bei den von ihm beschriebenen Lymphthromben im Haematolymphangioma mixtum machte.

Wie Wegner annimmt, sind die Lymphräume, die als Inbalt ein thrombusähnliches Gebilde haben, das Primäre. Dieser Inhalt wird von eindringendem Blute nach Analogie der Venenthromben kanalisirt, die Lymphe allmählich resorbirt und nun circulirt anstatt dieser in den Räumen Blut. Im Verlaufe des weiteren Entwicklungsganges sollen sich dann die Wandungen der Lymphräume gewissermaassen umwandeln und denen der Blutgefässe ähnlich werden. Wegner glaubt, dass bei der Berührung grösserer Lymphsäcke mit ektatischen Venen, deren beiderseitiger Inhalt unter hohem Druck steht, nachdem das Zwischengewebe geschwunden ist, ihre ohnehin schon vorher verdünnte Wand usurirt wird und nun das Blut, das in den Venen unter höherem Seitendrucke steht, in diese einströmt. Eine usurirte Wand zu finden und eine beginnende Communication nachzuweisen, ist Wegner nicht geglückt, ebensowenig Ritschl in seinen eingehenden Untersuchungen der Haematolymphangiome. Nur T $\sigma \mathrm{rök}$ will etwas Derartiges gesehen haben (doch liegt nach Ritschl kein zwingender Beweis in einer Abbildung vor). Möglicher Weise trifft ja die Annahme einer Usurirung der gegenseitigen Wände zu, und manche Autoren stützen diese Annalıme dadurch, dass sie diese Combination von Lymph- und Bluträumen des Haematolymphangioma mixtum an Körperstellen fanden, wo derartige Geschwülste häufigen Dehnungen, Zerrungen und Compressionen ausgesetzt waren, also z. B. an der Zunge, in den Inguinalbeugen und wie die Fälle von Ritschl an der Beugeseite des Vorderarms. Nicht nur die Druckverhältnisse, wie sie in höherem Grade in den Venen, als in den Lymphräumen vorhanden sind, werden als prädisponirende Momente angenommen, sondern auch rein mechanische Läsionen sollen ein Eindringen von Blut in die Lymphspalten begünstigen.

Wie deckt sich die letztere Annahme mit meinen Befunden? Die 
Geschwulsttheile liegen hier nirgends an Stellen, wo sie durch besondere Zerrungen u. s. w. irritirt werden könnten, besonders nicht die inneren Tumoren. Im Gegentheil sind namentlich letztere sehr geschützt, wenngleich es nicht ausgeschlossen ist, dass eventuell durch Bewegungen des Rumpfes kleine traumatische Verletzungen ein Schwanken des Inhalts bedingen könnten.

Alte Blutungen, die an vorhergegangene Traumen (vielleicht Massiren und Streichen) erinnern könnten, habe ich in grosser Menge in dem Bindegewebe der Fascie über der Rücken- und Thoraxmusculatur gefunden. Eine Deutung des hier angehäuften Blutpigments und ein Versuch, diese veränderten Blutbestandtheile mit den frischen Blutmassen in den Lymphräumen in Zusammenhang zu bringen, will mir nicht gelingen. Wie auch Ritschl erwähnt, braucht man für das Hineingelangen des Blutes in die Lymphgefässe nicht nur diesen Weg durch Usurirung der Wandungen. Ein viel natürlicherer ist noch geboten.

Da anzunehmen ist, dass das Blutgefässsystem mit den Saftspalten communicirt (J. Arnold, Thoma, Usk off) und somit durch die Stomata der dünnwandigen Capillaren Blutflüssigkeit sich in die Saftspalten ergiesst, so kann man auch weiter folgern, dass die Wanderung zelliger Elemente aus dem Blutgefässsystem in die Anfänge der Lymphwege ein normaler Vorgang ist. Ritschl bält es für denkbar, dass bei dem jedenfalls wohl erschwerten Lymphabfluss in spärlicher Menge ausgetretene Blutkörperchen in den Lymphräumen länger als sonst zurückgehalten und daher bisweilen in reichlicherer Anzahl angehäuft werden. M. E. dürfte aber wobl die reichlichere Anhäufung von rothen und weissen Blutkörperchen wesentlich darauf zurückzuführen sein, dass bei dem wohl ziemlich hohen Druck im Blutgefässsystem, bei dem constanten Turgor in diesen Tumoren, namentlich wenn gleichzeitig, wie in dem von mir untersuchten Falle eine cavernöse Angiombildung zum Theil vorliegt, mehr Blutelemente als unter normalen Verhältnissen zur Auswanderung in die nachgiebigeren Lymphräume veranlasst werden, abgesehen davon, dass vielleicht die Stomata bei der Erweiterung aller Hoblräume auch eine Erweiterung ihres Lumens erfahren dürften.

Eine Circulation des Blutes in dem Haematolymphangioma mixtum findet auf jeden Fall statt, denn man sieht nirgends in den Hohlräumen selbst Degenerationsproducte des Blutes, überall sind die rothen und weissen Blutkörperchen im Allgemeinen in ihrer Form gut erhalten. Eine Stagnation des Blutes liegt jedenfalls in den am reichlichsten mit Blut erfüllten Lymphräumen nicht vor. 
Epikrise.

Die Untersuchung lässt keinen Zweifel darüber, dass es sich an den drei Stellen um echte Geschwulstbildungen handelt, um multiple Lymphangiome, im engeren Sinne um multiples Haematolymphangioma mixtum.

Wir haben vor uns, wie bei den Angiomen und Lymphangiomen überhaupt, wohl congenitale Anomalieen unbestimmter Natur, welche die Anlage zur Geschwulst bilden, und dann ein weiteres Fortschreiten dieser angeborenen krankhaften Anlagen in die Nachbarschaft.

Bei dem enormen Lymphreichthum dieser Geschwülste, bei den so ausgedehnten und erweiterten Cystenräumen liegt es ja nahe, in erster Linie nach mechanischen Ursachen zu suchen, welche die Lymphstauung und die Erweiterung erklären könnten, und dies Streben ist um so natürlicher, als es Georg Wegner ja gelungen ist, mit mechanischen Hilfsmitteln eine Art von Lymphangioma cysticum herzustellen.

Ich habe nun meinen Fall unter Berücksichtigung der bisher aufgestellten Hypothesen möglichst sorgfältig untersucht, bin aber zu dem Ergebniss gekommen, dass die Sache nicht so einfach liegt, und dass man mit grob mechanischen Erklärungen nicht auskommt.

Als häufigsten Entstehungsmodus der Lymphangiome hat G. Wegner den durch Ektasie und Neoplasie, Dilatation vorhandener Lymphgefässe mit Neubildung von Wandungselementen angegeben. Er hat immer im Vordergrund gestanden gegenüber der homoplastischen und beteroplastischen Neoplasie.

Allmählich hat sich nun die Anschauung gebildet, dass bei der Entwickelung der Lymphangiome eine wirkliche Neubildung von Lymphgefässen (wobei ganz besonders die Lymphscheiden der Blutgefässe betheiligt sind) und zwar im Fettgewebe, das bekanntlich arm an präformirten Lymphgefässen ist, - daneben gleichzeitig eine Erweiterung derselben, eine Lymphangiektasie besteht. Im Allgemeinen nahm man an, dass diese durch eine Stauung zu Stande käme. Letztere sollte bedingt sein durch ein centrales, den Lymphabfluss behinderndes Moment, das vielleicht in einer Verengerung oder in einem Verschluss des Ductus thoracicus zu suchen gewesen wäre. Bei dem enorm ausgedehnten vorliegenden Falle wäre diese Annahme vielleicht berechtigt gewesen. Die Verfolgung dieses lymphabführenden Rohres hat jedoch dergleichen nicht ergeben.

Langhans, Esmarch und Kulenkampff haben die Ansicht gewonnen, dass die Ursachen der Störungen des Lymphabflusses in 
den Gewebsveränderungen an Ort und Stelle zu suchen seien. Diese Annahme kann ich hier nicht bestätigen, irgend welche Saftspalten und Kanälchen bieten doch den angestauten Lymphmassen Abflussmöglichkeiten. Auch Ritschl ist der Ansicht, dass das Ausbleiben von Stauungserscheinungen im Lymphsystem bei hochgradigem Verschluss auf das Vorhandensein von Collateralen zurückzuführen sei. Er kommt aber doch zu dem Schluss, dass man vorläufig an der bisherigen These als der der Wahrheit am nächsten kommenden festhalten müsse, welche die Stauungserscheinungen in den Lymphbahnen erklärt durch locale Hindernisse, die mit der Geschwulst entstehen.

Die Auffindung von Lymphthromben könnte ebenfalls beweisen, dass thatsächlich ein voller Abschluss um diese herum bestände, so dass in Folge der Stagnation die vollkommen abgekapselte Lymphe zur Gerinnung gebracht wäre. Derartiges aufzufinden ist mir nicht gelungen. Da Lymphthromben des öfteren bei Lymphangiomen kleineren Umfanges beobachtet sind, hätte sich in meinem ausgedehnten Falle ein solcher Befund wohl erwarten lassen. Aehnliche Gebilde, wie sie Wegner als Lymphthromben beschrieben, hätte ich an einzelnen Stellen vielleicht als solche gelten lassen können, doch scheinen mir diese bei der Härtung entstandene Kunstproducte vorzustellen. Die Hohlräume sind nicht abgeschlossen, sondern senden nach allen möglichen benachbarten kleine communicirende Kanälchen, haben also einen Abfluss. Das ist ohne Weiteres aus den Präparaten klar, sichtlich bewiesen auch schon dadurch, dass beim Anstechen eines grösseren Hohlraums aus vielen anderen auch ihr Inhalt heraussickert, bewiesen durch Injectionsversuche. Ein weiterer zwingender Beweis ist aber dadurch erbracht, dass es intra vitam möglich war, die Geschwulst der rechten Thoraxhälfte durch einen länger dauernden Druck zur Verkleinerung zu bringen. Dieses wichtige Moment deutet darauf hin, dass die mächtigen Lymphmassen, die in dem Tumor gewissermaassen angestaut, doch nicht zu einer Stagnation gezwungen, vielmehr Collateralbahnen oder Lymphspalten vorhanden sind, die eine Abflussund Circulationsmöglichkeit bieten. Es wird m. E. nun dadurch auch klar, dass in dem Tumor nirgends Lymphthromben aufzufinden waren. Bis zu einem gewissen Grade kann man daraus entnehmen, dass man die Ansicht, die Ursachen der Störungen des Lymphabflusses seien in den Gewebsveränderungen, $d . h$. in einem Verschluss der abführenden Wege durch Bindegewebs- oder Endothelwucherung an Ort und Stelle zu suchen, nicht als vollkommen erwiesen aufrecht erhalten darf.

Neben den erwähnten Anschauungen ist, seitdem Heiden hain 
eine Secretion der Endothelien als wahrscheinlich angenommen hat, des öfteren daran gedacht, die massenhafte Lymphe in den Lymphgeschwülsten auf eine vermehrte Thätigkeit der auskleidenden Wandelemente zurückzuführen.

Mir scheint eine Lymphsecretion der Endothelien beim Lymphangiom mindestens sehr problematisch. Jedenfalls ist das auf dem Wege mikroskopischer Untersuchung überhaupt nicht zu entscheiden.

Nun sind die Lymphangiome Geschwülste, bei denen Lymphgefässe und massenhafte Lymphräume den charakteristischen Bestandtheil bilden. Aber nicht nur die Neubildung und Erweiterung dieser ist das Wesentliche; nicht nur Fettgewebe, in dem sich die Proliferationsprocesse zunächst abspielen, das die Matrix dieser Gebilde ist, umgiebt die Gefässe, Spalten und Räume, auch überaus reichliches Bindegewebe umscheidet sie und stellt das Gerüst dieser zerklüfteten kammerigen, schwammigen Tumoren.

Nas se führt an, dass das Bindegewebe entsprechend der Dilatation der Lymphgefässe vermehrt war, nirgends Erscheinungen von Schrumpfung zeigte und einem wuchernden jungen Gewebe glich; ferner, dass in vielen, sicher in einigen Fällen eine Bildung neuer Bahnen stattfindet, die oft mit einer Hyperplasie des Binde- oder Fettgewebes verbunden ist.

Ritschl hebt besonders hervor, dass der Neubildung von Bindegewebe, wie es ihm besonders im peripheren Theile der Geschwulst entgegentrat, bisher ein viel zu geringer Antheil an dem Aufbau und auch an den Veränderungen der Lymphgefässe zugeschrieben ist.

In neuerer Zeit hat besonders Ribbert auf die Bedeutung des Bindegewebes bei der Entwicklung der Lymphangiome aufmerksam gemacht; darauf, dass die Bindesubstanz nicht etwa durch primäre Erweiterung der Lymphräume auseinandergedrängt wird, sondern durchaus selbständig neugebildet und offenbar noch im Wachsthum begriffen ist, dass sein Wachsthum zur Vergrösserung der Wandfläche und damit zur Erweiterung des Lumens der Lymphräume führt.

Schon Virchow führt bei der Besprechung der Vergrösserung der cavernösen Angiome aus, dass eine fortschreitende Reizung eintritt, das Nachbargewebe zur Granulation veranlasst, und dass das granulirende Gewebe neue Gefässe erzeugt. Ein ähnlicher Vorgang ist ersichtlich in den ersten Stadien der Lymphangiombildung. Das Fettgewebe -, das sowohl während seiner embryonalen Entwicklung (Flemming) als auch später bei seinen Vermehrungsvorgängen im fertigen Organismus von der Adventitia der Blutgefüsse ausgeht und die Fähigkeit besitzt, unter Umständen bei seiner Ruckbildung in 
Bindegewebe wieder protoplasma- und kernhaltig zu werden - wird kernreicher, in ihm werden Lymphgefässe gebildet, es wird vermehrt und in den die Lymphgefässe begrenzenden Theilen zu Bindegewebe umgewandelt. Schritt fïr Schritt kann man beobachten, wie das Bindegewebe entsprechend der Vergrösserung der Lymphräume das Fettgewebe verdrängt, ersetzt und zugleich mächtig zunimmt. Es ist überall auffallend kernreich, besonders in den den Lymphräumen abgewandten Theilen. Dass es aber auch noch direct unter dem wachsenden Endothel in starker Wucherung begriffen ist, sieht man nur zu deutlich an den polypösen Vorsprüngen, welche kernreich sich 'in das Lumen der Räume hineinwölben (Ribbert). Aus den zarten bindegewebigen Wänden der kleineren Lymphräume werden die dickeren Wände der grösseren in der allmählich wachsenden Geschwulst. „Das Wachsthum des Bindegewebes sammt dem Endothel und die Dilatation der Hohlräume gehen stets Hand in Hand." "Lymphräume und Bindegewebe hängen eng zusammen" (Ribbert).

Die Beobachtungen Ribbert's über das ständig mitwachsende Bindegewebe kann ich vollauf bestätigen. Ich fand aber weiterhin in den breiteren Bindegewebszügen annähernd proportional der $\mathrm{Zu}$. nahme der Bindegewebsfibrillen eine Entwicklung von elastischen Fasern, die allerdings nie in dickeren Bündeln anzutreffen waren, sondern überall zerstreut der, wenn man so sagen darf, concentrischen Schichtung um die Lymphräume entsprechend verliefen. Wie das Bindegewebe, so scheinen auch sie von dem adventitiellen Bindegewebe der Gefässe und ihren elastischen Bestandtheilen herzukommen.

Auch ein Vorhandensein von glatten Muskelfasern war zu constatiren, natürlich nur in den vorgerückteren Theilen der Geschwulst.

Möglich wäre es vielleicht, dass in Folge des Vorhandenseins von elastischen Fasern und glatten Muskelfasern die Lymphräume befähigt wären, eine gewisse Circulation der in ihnen vorhandenen Lymphe ins Werk zu setzen und einen Austausch von Lymphe und lymphatischen Elementen hervorzubringen. Andererseits könnte eine gewisse Contractionsfähigkeit dazu befugt sein, durch eine gewissermaassen hervorgebrachte Verengerung, z. B. an den abführenden Bahnen, einen grösseren Turgor in den Geschwülsten hervorzubringen, sodass dann prall elastische Tumoren daraus würden, die Robin, wenn auch an anderen Körperstellen, als Tumeur éréctile lymphatique bezeichnet hat.

Am einfachsten scheint es mir, Mangels sicher nachweisbarer mechanischer Factoren anzunehmen, dass in den pathologiseh angelegten Blut- und Lymphgefässbezirken eine vasomoto- 
rische Innervation dauernd besteht, wie wir sie in Geweben mit normalem Blut- und Lymphgefässsystem zu Zeiten des Turgors, der activen Hyperämie antreffen. Es strömt reichlich Blut und Lymphe in die Capillaren ein, und trotz offener Abzugskanäle fliesst nur so viel $a b$, als Ueberschuss über die volle Anfüllung aller Gefässlichtungen zugeströmt ist. Dem entspricht die Beobachtung der Erectilität. Dieser Turgor genügt vollauf, die nothwendige mechanische Ausdehnung zu erklären.

Eine Deutung des Proliferationsprocesses müssen wir aber offen lassen, denn mit allen möglichen Drucksteigerungen bringen wir weder Varicen, noch Angiome oder Lymphangiome hervor. Der Wachsthumsimpuls der meisten Geschwülste ist uns ja leider noch vollkommen unbekannt und räthselhaft.

In der Literatur habe ich keinen analogen Fall von intraabdominalem Lymphangiom gefunden, immerhin meine ich, sind wir zu einer befriedigenden Erklärung gekommen.

Anders im II. Falle.

Lymphcyste am Coecum.

Hier handelt es sich um eine jener seltenen retroperitonealen Cysten, die zu beiden Seiten der Wirbelsäule hauptsächlich in der Umgebung der Nieren gefunden sind. Sie sitzen der hinteren Bauchwand breit auf und schieben das Peritoneum parietale vor sich her. Manche von ihnen erreichen eine erhebliche Grösse und können dann das Colon ascendens oder descendens vor sich herdrängen, das zu ihnen gehörige Mesocolon gewissermaassen spalten und dann auch dem Colon unmittelbar anliegen.

Aus der mir von Herrn Prof. Dr. Krehl gütigst überlassenen Krankengeschichte möchte ich nur kurz erwähnen, dass die 56 jährige Frau Sophie St. vom 29. April bis 12. Juli 1901 wegen eines Oesophaguscarcinomes auf der medicinischen Klinik zu Greifswald behandelt wurde und hier ihrem qualvollen Leiden erlag.

Von Wichtigkeit ist der Befund des Abdomens: Abdomen sehr flach, die Bauchdecken fettfrei, nicht aufgetrieben. Der obere rechte Theil wird ausgefullt von einem Tumor mit sehr praller Consistenz. Drei Finger breit unter dem Processus xiphoidens, etwas rechts von der Mittellinie, fühlt man eine etwa gänseeigrosse Hervorwölbung des Tumors, die dieselbe Consistenz wie der ubrige Tumor hat. Der Leberrand ist nicht deutlich abzugrenzen, auch ist der Tumor beim Athmen nicht deutlich verschieblich. Die Ausheberung des Magensaftes gelingt nicht, etwa $35 \mathrm{~cm}$ von der Mundöffunng entfernt stösst man auf eine Stenose, weswegen von einer weiteren Untersuchung Abstand genommen wird. An der Sonde etwas Blut. 
Bei der Palpation am 16. Juni ist rechts von der Mittellinie, in der Gegend der Gallenblase ein $7 \mathrm{~cm}$ langer, $4 \mathrm{~cm}$ breiter, sehr harter wurstförmiger Tumor, der sehr schmerzempfindlich ist, zu constatiren. Leber in Ganzen hart, die starre Resistenz geht bis in die Milzgegend hinein. Die Milz ist nicht als solche davon abzutasten.

Die am 13. Juli ausgefthrte Section ergab nachstehenden Befund.

Aeusserst abgemagerte weibliche Leiche, mit schlaffer Haut und zahlreichen Runzeln auf dem Bauche. Das Fettgewebe ist auf der Schnittfläche von braungelber Farbe. Aus der Bauchhöhle entweicht weder Flussigkeit noch Gas. Im Becken etwa $10 \mathrm{ccm}$ klarer Flüssigkeit. Hinter dem Colon ascendens wölbt sich zu beiden Seiten eine eystische Geschwulst vor und lässt sich bis ins Mesenterium hineindrucken. Es handelt sich um eine Lymphanhäufung hinter und za beiden Seiten des Colon ascendens. Der Magen reicht mit seiner Pars pylorica bis unter den Nabel herab. Das Colon transversum liegt an der Symphyse.

Nach Herausnahme des Brustbeins retrahiren sicli beide Lungen gleichmässig stark. Im linken Pleuraraum $100 \mathrm{ccm}$ klarer Flı̈ssigkeit. Die Lungen reichen oben bis an die Mittellinie, unten bleibt ein etwa handtellergrosser Theil des Herzbeutels frei. In demselben etwa $75 \mathrm{ccm}$ klarer Flitssigkeit. Pericard spiegelnd glatt und glänzend, Herz von der Grösse der Fanst der Leiche. Das Fettgewebe ist bis auf eine glasige Masse geschwunden. Die Kranzarterien als dicke geschlängelte Wulste fühlen sich hart an. Das linke Herz ist sehr viel umfangreicher und fester als das schlaffe rechte. Aus dem rechten Vorhof entleert sich wenig flíssiges und geronnenes Blut. Der rechte Ventrikel enthält geronnenes Blut, ist sehr schlaff, der linke fest contrahirt. Die venösen Klappen sind für zwei Finger bequem durchgängig, die arteriellen schliessen auf Wassereinguss. Farbe der Musculatur braunroth. Linker Ventrikel $9 \mathrm{~cm}$ lang. Aorta $8 \mathrm{~cm}$ breit, Myocard links 19, rechts $4 \mathrm{~mm}$ dick. Endocard und Klappen intact.

Linke Pleura tberall spiegelnd glatt, glänzend. Im Unterlappen enthält sie nur an einer Stelle ein submiliares Knötchen von glassig grauem, markigem Aussehen, auf dem Durchschnitt etwa $1 \mathrm{~mm}$ dick, in dessen Umgebung viele Blutadern zu erkennen sind. Oberlappen überall lufthaltig. Pleura des Unterlappens an einzelnen Stellen blauroth. Diese Stellen grenzen sich scharf ab und liegen im Niveau tiefer, der Unterlappen fühlt sich z. Th. fest an, man fühlt einzelne kleine Knötchen durch. Die Bronchien enthalten Eiter.

Die rechte Lange wird im Zusammenhang mit dem ganzen Oesophagus, Halsorganen und Magen herausgenommen. Die Schleimhaut des Rachens zeigt keine pathologische Veränderung. In der Mitte der Speiseröhre, etwa an der Kreuzung des linken Bronchus, befindet sich ein grosses, $10 \mathrm{~cm}$ langes, flaches Geschwür mit zerkluftetem Grund und nekrotischen Geschwulstmassen. Die Ränder des Geschwürs sind erhaben and fublen sich fest an. Das Geschwür ist an keiner Stelle in die Hohlräume der Nachbarschaft perforirt. Die rechte Lunge ist allerdings so adhärent, dass sie nicht abgetrennt werden kann, da der Krebs auf die Pleura ubergewuchert ist. In ibrem Oberlappen ist sie lufthaltig, im 
Unter- und Mittellappen derb. Auf der Schnittfäche findet sich sehr reichlicher Gewebssaft. Die Bronchien enthatten Eiter, aber an keiner Stelle ist die Schleimhaut mit Carcinom infiltrirt. Der Magen hat eine gelbliche opake, glatte Schleimhaut.

Milz, Nieren, Rectum und Genitalorgane zeigen keine besonderen pathologischen Veränderungen, ebensowenig Leber und Gallenblase.

Pathologisch-anatomische Diagnose:

Atrophia fusca cordis, Atrophia gelatinosa telae adiposae subpericardialis, Atelektasis lobi inf. utriusque pulmon. Oedema pulmon. dextr. Bronchopneumonia multiplex. Bronchitis catarrhalis.

Carcinoma oesophagi. Infiltratio carcinomatosa pleurae dextrae.

Das Cöcum und Colon ascendens sind im Zusammenhang mit der oben erwähnten cystischen Geschwulst herausgenommen. Dabei zeigt sich, dass beide, namentlich das stark ausgedehnte Cöcum, aus ihrer gewöbnlichen Lage durch die Geschwulst emporgehoben sind. Letztere ragt zu beiden Seiten neben dem Colon ascendens etwa eine Hand breit vom unteren Cöcumpole entfernt hervor. Der prall-elastische Tumor zerfällt, oberflächlich betrachtet, in mehrere Cysten von Taubenei- bis Gänseeigrösse. Ihr Inhalt lässt sich zum Theil wegdrücken, wobei sich nach theilweiser Entleerung der einen, andere Räume praller füllen. An der Vorderseite des Colon ascendens sind die grossen Cysten ungefähr zwei Finger breit von einander entfernt. Auf der Hinterseite befinden sich die grösseren Tumormassen. Durch den Ansatz des linken Mesocolonblattes oder vielmehr durch dieses und die in seiner Verlängerung liegende Taenie scheinen die Cysten in linke und rechte getrennt $\mathrm{zu}$ sein und ihrerseits mit einander $\mathrm{zu}$ communiciren. Der Cystencomplex auf der rechten Seite ist der bei Weitem grössere. Nicht mit Sicherheit ist zu sagen, ob er sich weiter oberhalb in den linken fortsetzt. Das Peritoneum ist vom Coecum und Colon ascendens durch den grossen Cystenverband nach vorn abgehoben und bedeckt mit seinem visceralen Blatt, also nur das Coecum zum grössten Theile und einen schmalen Streifen des Colon ascendens zwischen den von rechts und links vorwachsenden blasigen Gebilden. Unten schneidet die cystische Geschwulst scharf mit der rechten Linea innominata $\mathrm{ab}$, nach oben begiebt sie sich, in der Nähe der Wirbelsäule sich haltend, bis unter die rechte Niere, sodass diese nach links einwärts ab- und emporgehoben ist, die cystische Geschwulst also zwischen dem unteren Nierenpol und der Fascie der Rückenmusculatur sich ausgebreitet hat. Die Präparation aus dem umgebenden Gewebe nach Durchtrennung des Peritoneums, die Ausschälung ist ohne besondere Schwierigkeit glatt auszuführen, dabei fliesst nirgends Lymphe aus. 
Zur mikroskopischen Untersuchung wurde ein kleiner Theil vom oberen $\mathrm{Pol}$ der Cyste entnommen. Es findet sich, dass die Wand aus einem dünnen Bindegewebe besteht und mit einem continuirlichen, zarten einschichtigen Endothel ausgekleidet ist.

Der Inhalt besteht aus lymphatischer Flüssigkeit.

Wir haben also eine Lymphcyste vor uns, die hinter dem Colon ascendens, dasselbe nach vorn drängend, gelegen ist, hinter dem Peritoneum unterhalb der rechten Niere, eine vollkommen abgeschlossene mehrkammerige Cyste, die mit keinem der benachbarten Organe in irgend welchem Zusammenhang steht.

Letzteres geht daraus hervor, dass dieselbe sich leicht ohne besondere Mühe herauspräpariren lässt, ohne irgend eine Einbusse ihres Inhalts zu erleiden.

In der Literatur finden sich nur wenige ähnliche retroperitoneale Cysten; am ähnlichsten dem oben beschriebenen Falle ist der von Kilian (Berliner klin. Wochenschrift. 1886. Nr. 25, S. 407), wo eine Lymphcyste bei einer älteren Frau in der rechten Oberbauchgegend unterhalb der Leber in Nabelhöhe nach aussen von ihm prominirte. Sie wurde theilweise von der rechten Niere oben bedeckt, den unteren Pol der Niere nach links drängend; das Colon ascendens lag vor ihr und verlief ron unten rechts nach links oben. Der Inhalt bestand aus einer weiss-grauen, geruchlosen, alkalischen Flussigkeit. Entstehung aus dem Ductus thoracicus.

Eine zweite retroperitoneale Cyste ist von Narath (Archiv für klin. Chirurgie. Bd. L.) bei einem 52jährigen Bulgaren beschrieben worden. Sie lag auf der linken Seite und drängte das Colon descendens nach vorn, letzteres querte dann tief unten das Querstück des Tumors, der ausging von der Gegend zwischen Ureter und Vena spermatica interna, medial von der linken Niere. Sie enthielt 41 gelbgrünlicher Flüssigkeit, viel Albumen, kein Cholestearin, mit massenhaften Fetttröpfehen. Narath hält eine Entstehungsweise aus dem linken Plexus lymphaticus lumbalis oder aus einzelnen lumbalen Lymphdrüsen für möglich.

Winter hat eine dritte retroperitoneale Cyste in der Zeitschrift für Geburtshilfe und Gynäkologie. 1895. Bd. XXXIII. S. 210 (Verhandlungen der Gesellschaft für Geburtshilfe und Gynäkologie. 28. Juli 1895, Berlin) aufgeführt. Sie hatte sich oben zwischen Leber und Colon transversum hinter dem Lig. hepatorenale entwickelt als mannskopfgrosser Tumor mit wasserhellem, eiweissarmem Inhalt. Die Wand der Cyste mit deutlichem Endothel ausgekleidet, zeigte bindegewebige Structur. Entstehung: dilatirtes Lymphgefäss. 
Nach dem Inhalt und der Auskleidung der von mir gefundenen Cyste ist dieselbe als retroperitoneale Lymphcyste den eben erwähnten Fällen anzureihen.

Die Entstehung solcher Cysten wird, wie schon oben angefübrt, auf eine cystische Entartung von Lymphdrüsen, auf eine Erweiterung grösserer lymphatischer Bahnen zurückgeführt.

In meinem Falle muss zunächst vollkommen die Möglichkeit einer Entstebung aus der Cysterna chyli oder dem Truncus lymphaticus intestinalis ausgeschlossen werden, da beide zu entfernt von der Wurzel der Cyste, die sich im Mesocolon an der hinteren Taenia des Colon ascendens gefunden, liegen.

Der zweite Modus der Entstehung aus Lymphdrïsen ist mir auch recht unwahrscheinlich, denn die hier in Frage kommenden wären die des Ileocöcalstranges, jenes Abschnittes des Lymphsystems, der bei den mannigfachsten Darmerkrankungen mehr oder weniger stark betheiligt ist. Sie können wegen ihrer medialen Lage zu der eigentlichen Geschwulst in keine Beziehung gebracht werden.

In Frage kann nun noch weiterhin das Lymphgefässsystem kommen, insofern als vielleicht ein cystische Erweiterung eines grösseren Lymphgefässes, das in seinem oberen Theile verschlossen, durch die Aufnabme der von der rechten unteren Extremität oder den in der Nähe des Cöcum gelegenen Theile absickernde Lymphe erweitert, stark dilatirt und nachher vielleicht durch an dem Anfangstheile gewucherte Endothelien abgeschlossen worden wäre.

Oder es könnte ein retrocöcales Lymphangioma cavernosum eventuell cystisch entartet und zu einem Lymphangioma cysticum geworden sein, da die Cyste grosse Aebnlichkeit zeigt mit den von Wegner durch Einbringen von grossen Mengen Luft in die Bauchböhle experimentell erzeugten Cysten, die den Typus des Lymphangioma cysticum darstellen. Der Schwund der einzelnen Septen zwischen den kleineren und grösseren Cysten ist leich erklärlich durch Druckatrophie von Seiten der vermehrten und unter einem relativ hohen Drucke stehenden Flüssigkeit.

Scbliesslich könnte man noch an eine Möglichkeit der Entstehung denken. Wie das subepicardiale Fettgewebe des Herzens. bei alten mangelhaft ernährten Individuen leicht der gallertigen Atrophie anheimfallen kann, wie der Sectionsbefund dieses Falles auch lehrt, so könnte man auch geneigt sein, anzunehmen, dass vielleicht das hinter dem Cöcum und dem Colon ascendens gelegene Fettgewebe in den Zustand der gallertigen Atrophie übergehen künnte, zumal das Bindegewebe der Cystenwand einen ganz kärglichen, atrophischen $\mathrm{Zu}$ - 
stand bietet. Die Auskleidung der Wand mit Endothel würde dabei nicht Wunder nehmen, da man schlechterdings in auf solche Art und Weise entstandenen Cysten einen anderen Wandbelag kaum erwarten dürfte.

Eine ausgedehntere Untersuchung der Cystenwand habe ich unterlassen in Rücksicht auf die Erhaltung des interessanten, nicht zu den alltäglichen Vorkommnissen zählenden Präparates.

Entstehungsmöglichkeiten der verschiedenen Art habe ich angeführt, ein zwingender Beweis für die sichere Entwicklung auf einem der angezeigten Wege scheint mir bisher weder überhaupt erbracht, noch ist es mir geglückt, eine wirkliche Erklärung zu finden, die ihre Schwierigkeit auch besonders in dem Umstand hat, dass die Anfangsstadien der Cystenbildung bei dem grossen Umfange dieser retroperitonealen Lymphcyste nirgends nachzuweisen waren.

Klinisch dürfte von Wichtigkeit sein, dass dieser retroperitoneale Tumor subjectiv keine besonderen Beschwerden gemacht hat, er war bei der abgemagerten Frau deutlich zu palpiren, zeigte aber dabei eine gross: schmerzempfindlichkeit.

\section{Fall.}

Im Anschluss an die eben beschriebene retroperitoneale Lymphcyste möchte ich eine durch Operation gewonnene abdominelle Cyste besprechen, die am 25. Juli 1901 dem pathologischen Institut zu Greifswald zur Untersuchung übersandt wurde.

Dieselbe war von Herrn Oberstabsarzt Professor Dr. Alberti im St. Josephskrankenhaus-Potsdam exstirpirt. Die Diagnose war gestellt auf ein Angioma cysticum mesenteriale. Für die Ueberlassung des Falles sowie für die Krankengeschichte erlaube ich mir Herrn Professor Dr. Alberti meinen besten Dank auszusprechen.

Krankengeschichte.

Die am 22. Juli exstirpirte mesenterielle Cyste stammt von einem 31/4 Jahre alten Knaben, der nach Angabe der Eltern bis zum 17. Juli 1901 gesund war. An diesem Tage klagte er über Schmerzen im Leib und fiel den Eltern die starke Vorwölbung der rechten Seite des Leibes auf. Das Kind wurde am 20. Juli unter der Diagnose eines Lebertumors hier eingeliefert. Er machté bei seiner Aufnahme einen sehr schweren Krankheitseindruck. Puls und Respiration waren auffallend beschleunigt, es bestand hohes Fieber (über 390) und starker Husten mit katarrhalischen Erscheinungen tiber der rechten Lungenspitze, weshalb an einen Zusammenhang mit Tbc. gedacht wurde. In der rechten Seit des Abdomens war eine etwa kindskopfgrosse Geschwulst zu palpiren, die unterhalb der Leber begann, nach unten bis zur Becken- 
schaufel reichte und nach links die Mittellinie uberschritt. Der Tumor erwies sich deutlich als unabhängig von der Leber. Bei der Operation zeigte es sich, dass es sich um eine prall gefiillte, solitäre, mesenteriale Cyste handelte, die ungefähr einen Liter wasserklarer Flüssigkeit enthielt. In der Tjmgebung der Cyste fanden sich mehrere, uber bohnengrosse, bläulich verfärbte Drüsen, von denen wegen der Gefahr einer stärkeren Blutung nur einige mitentfernt werden konnten. Die Vena cava inf. musste in einer Ausdehnung von etwa $5 \mathrm{~cm}$ freigelegt werden. Das Befinden des kleinen Patienten hat sich nach dem operativen Eingriff zusehends gebessert. Puls und Respiration sind regelmässig, die Temperatur ist normal. In den ersten Tagen nach der Operation trat aus der Bauchwunde eine die Haut leicht ätzende Flüssigkeit von unangenehmem, fadem Geruch; es diirfte sich wohl um eine durch Läsion bei der Operation entstandene Pankreasfistel gehandelt haben. Dieselbe ist jetzt sehon wieder geschlossen.

Das Kind befindet sich in Reconvalescenz.

Die Cyste kam in Formalin gehärtet hier an, weshalb eine frische Untersuchung nicht mehr stattfinden konnte. Ueber die Beschaffenheit des Inhalts habe ich leider ausser der Angabe, dass derselbe aus einer wasserklaren Flüssigkeit bestanden, nichts erfahren können.

Die Epithelien der Wand, die ich in gehärtetem Zustand durch Abschaben gewinnen konnte, hatten eine flache Form, ähnlich den Endothelien der Lymphcysten, sodass aus diesen und der äusseren Gestalt zunächst auf eine solche geschlossen wurde.

Die annähernd kindsk opf grosse Cyste ist von ovaler Gestalt, an der Vorderfläche von Peritoneum uberzogen. Am oberen Pole finden sich etwa bohnengrosse Gebilde, die in innigem Zusammenhang mit der Wand stehen. An der hinteren Fläche durchtrenntes Binde- und zartes Fettgewebe. Aufgeschnitten zeigt sich im Allgemeinen eine glatte Innenfläche, die hier und da kleine Ausbuchtungen, vereinzelt kleine balkenähnliche Gebilde darbietet. Im oberen Pole ein kleiner Recessus, der nach den äusserlich als bohnengrosse Knoten imponirenden Gebilden hinzieht. Die grösste Dicke der Cystenwand beträgt $6 \mathrm{~mm}$, an einzelnen Stellen, besonders nach vorn unten zu, ist sie etwas geringer.

Zur mikroskopischen Untersuchung werden verschiedene Stïcke aus der Wand entnommen und auch Stiucke von den am oberen Pole als Drüsen angenommenen Gebilden. Bei der Entnahme der letzteren zeigt sich, dass sie dicht über dem Cavum der Höhle, nur durch eine geringe $Z$ wischenschicht getrennt liegen.

Mikroskopischer Befund. Die Cystenwand ist mit einem geschichteten cylinderförmigen (Uebergangs-)Epithel bekleidet, welches an einzelnen Stellen aber nur aus einer einfachen oder doppelten Lage 
besteht. Darunter ein derbes Bindegewebe, das von mehr oder weniger zahlreichen Blutgefässen durchzogen ist. Hie und da sind glatte Muskelfasern eingeflochten.

Schnitte aus dem oberen Pole und den drüsenähnlichen Gebilden bringen nun merkwürdige Ueberraschungen.

Das Epithel der Innenwand, welches hier schlauchartige zum Theil tiefe Einsenkungen zeigt, ist in der Iauptsache einschichtig, von mehr oder weniger hoher cylindrischer Form, hieran schliesst sich derbes faseriges Bindegewebe mit reichlichen Blutgefässen, die durchweg aber eine stark verdickte Wand zeigen. Es folgt theils zarteres, theils stärkeres Bindegewebe, mit auffallend reichlichen Zügen glatter Musculatur und saftigem kernreichen Bindegewebe. In diesem Gebiete sind vereinzelt langgestreckte Kanäle, theils mehr, theils weniger gebuchtet, z. Th. sind es erweiterte Räume, in die sich papilläre oder leistenförmige Vorsprünge einstülpen mit einem hohen cylindrischen Epithel. Durch bindegewebige Schicht getrennt, in der grösserer Kernreichthum vorherrschend ist, liegt peripherwärts ein Gebiet mit langen geraden Kanälchen, die einen deutlichen cylindrischen Epithelbelag auf einer Membrana propria ruhend zeigen, weiterhin mit gewundenen Harnkanälchen und deutlichen Glomeruli. Im Bereich der gewundenen Harnkanälchen ist vielfach adenomähnliche Structur zu constatiren. Stellenweise findet sich eine reichliche Ansammlung von Rundzellen im interstitiellen Gewebe, bisweilen anch bindegewebige Verdickung der Glomeruluskapseln und bindegewebige Verödung einzelner Glomeruli.

Uarnkanälchen sowohl wie die Glomeruli stehen auf der Höhe einer vollkommen ausgebildeten Entwicklungsstufe. Eine cystische Entartung derselben ist in dem peripherischen Gebiete nirgends wahrzunehmen.

Nach dem mikroskopischen Befund war es nicht mehr zweifelhaft, dass wir vor uns ein grosses cystisches Gebilde hatten, das aus der rechten Niere hervorgegangen ist, eine hochgradige Hydronephrose, die ganz allmählich sich entwickelt und erst durch ihre endlich erreichte Grösse Beschwerden verursucht hatte.

Das Nächstliegende war nun, nach dem Ureter dieser Hydronephrose zu suchen. Mit einiger Mühe gelang es, ihn zu finden.

Im oberen Drittel der Cyste ragt an der hinteren Fläche in schräger Richtung inserirend ein kleiner Stiel hervor, mit einem Lumen ungefähr von der Dicke des Ureters eines Neugebornen, durch dieses Gebilde kommt man ins Innere der Cyste. Hier ist ein enger Spalt sichtbar, der eine nach oben convexe halbmondförmige Klappe trägt, unter der sich buckelförmig ein kleiner derb sich anfühlender Wulst von über Hirsekorngrösse hervorwölbt, das Lumen nach aussen 
hin abschliessend und so das Durchdringen einer feinsten Sonde leicht erschwerend.

Von Koblanck und Pforte ist vor Kurzem bei einem ähnlichen Falle (ältere Frau) darauf hingewiesen worden, dass sich ein mehrschichtiges cylindrisches Epithel als Auskleidung der betreffenden Hydronephrose vorgefunden hat. Auch in dem vorliegenden Falle habe ich in dünnen Schnitten an den am stärksten dilatirten Stellen ein deutliches, schön erhaltenes, z. Th. abgeflachtes cylindrisches Epithel gesehen, während an dem dickeren Theile der Wand in der Nähe der erhaltenen Nierensubstanz das Epithel der schlauchartigen und verzweigten Einsenkungen von hoher cylindrischer Form ist. Jedenfalls sind alle Epithelien schön erhalten, sodass von einem nahen Zerfall oder Zugrundegehen der die Cyste auskleidenden Wandelemente nicht die Rede sein kann, wenn auch zugegeben werden muss, dass durch die lange Zeit bestehende Staung und den Druck des Urins eine Abplattung der Epithelien, des erweiterten Nierenbeckens natïrlicher Weise bedingt worden ist.

Eine auffallende Erscheinung ist der Reichthum an glatten Muskelfasern in der Wand des bydronephrotischen Sackes. Die Vermehrung dieser Bestandtheile ist ausgegangen von den normalerweise im Nierenbecken vorhandenen glatten Muskelfasern. (Die Annahme, dass eine Wucherung der Musculatur der Nierenkapsel bis in diese Tiefe stattgefunden, ist schlechterdings nicht zu erhärten.) Nicht unmöglich erscheint es mir, dass bei dem Bestreben, die angestauten Harnmassen aus dem Nierenbecken herauszubefördern, in Folge continuirlicher Contractionen die glatten Muskeln eine Zunahme erfahren haben, ähnlich wenn auch nur ganz entfernt, wie bei der trabeculären Hyperplasie der Blasenmusculatur in Folge von vorgelagerten Hindernissen z. B. Stricturen oder Prostatahypertrophie.

Dass gleichzeitig mit der Ausbildung der Hydronephrose eine interstitielle Entzündung bestanden, ist nur zu natïrlich.

Wie allgemein angenommen, ist die Hydronephrose eine exquisit mechanische Affection, deren ganzes Wesen sich in der Störung der Behinderung des Harnabflusses erschöpft. An der uns übersandten Sackniere nun findet sich ein anscheinend normaler Ureter, der jedoch eine schiefe Implantation in das Nierenbecken hat, und über dessen innerer Mündung eine nach oben convexe Klappe in leiser Berührung mit der unteren Ureterwand ist, welche eine buckelige Vorwölbung trägt. Ein weiter distalwärts vom Nierenbecken gelegenes Hinderniss hat die Erweiterung nicht bedingt, sonst hätte der Ureter bis zum Nierenbecken auch ausgedehnt sein müssen. 
Die Hydronepbrose ist hervorgerufen durch ein mechanisches Moment, das in dem klappenförmigen Verschluss des Ureters am Nierenbecken bedingt ist.

Möglich, dass die schiefwinklige Insertion congenital ist, wie von Engliseh und Cohnheim angenommen wird, möglich aber auch, dass der schiefe Ursprung nach der Ansicht Simon's durch eine Drehung der Niere in Folge der Ausdehnung ihres Beckens erworben ist.

Ich möchte glauben, dass eine gewisse schiefe Implantation des Ureters im obigen Falle angeboren ist, dass vielleicht eine vorübergehende entzündliche Schwellung der Schleimhaut des Nierenbeckens, die sich auf ihrer Unterlage verschieben kann und dem Zug der Strömung folgend über die Oeffnung des Ureters hinweggezogen wird und so die Klappe bildet ( $K$ üster), die Abflusspforte verlegt hat. In Folge dieser angenommenen vorübergehenden Verlagerung hat sich durch Urinretention das Nierenbecken erweitert. Mag auch ab und zu noch eine Durchgängigkeit des verlegten Ureters bestanden haben, so ist nun doch successive eine Vergrösserung des Nierenbeckens eingetreten, zugleich in Folge der starken Flüssigkeitsansammlung ein vermehrter Zug des ganzen Sackes (wie Hansemann dies in seinem Beitrag zur Mechanik der Hydronephrosen aufstellt) dem Gesetz der Schwere folgend nach unten und vorn zu nach der freien Bauchhöhle. Da nun der Ureter in der Gegend seines Austritts, wie Englisch nachgewiesen, besonders stark fixirt ist, so ist die natürliche Folge des Zuges, dass die Uretermündung nach unten verlagert und so gleichzeitig die obere vordere verschliessende Klappe vergrössert in enge Berührung mit der unteren, hinteren Wand des Ureters tritt. Der fast völlige Schluss der Klappe ist erreicht. Dem Abfluss des Urins ist eine nicht zu überwindende Schranke gesetzt. Die Folge ist eine sehr beträchtliche Harnstauung, Vergrösserung des Sackes, allmähliche Verödung der Markkegel, fast der ganzen Niere subjective Beschwerden des Trägers der Hydronephrose.

An dem Zustandekommen dieser Sackniere sind m. E. alle eben angeführten Momente betheiligt gewesen.

$\mathrm{Ob}$ bereits auch congenital ein gering erweitertes Nierenbecken vorhanden war, ist nicht zu ermitteln, eine fehlerhafte Anlage der Niere auszuschliessen, ist man aber berechtigt durch den Befund vollkommen ausgebildeten Nierenparenchyms.

Der vorliegende Fall von allmählich entstandener Hydronephrose bei einem $31 / 4$ Jahre alten Knaben dürfte jedenfalls ein nicht uninteressanter Beitrag zu den abdominellen Cysten und ihrer Ent- 
wicklung sein, zugleich ein kleiner Hinweis darauf, jede abdominelle Cyste einer genauen mikroskopischen Untersuchung zu unterwerfen, damit man, sollte der Fall ciner späteren Nierenexstirpation z. B. bei demselben Individuum eintreten, Kenntniss von dem Fehlen einer Niere hat.

\section{Fall.}

Noch kurz möchte ich über eine zufällig bei der Section gefundene abdominale Cyste berichten, die für die Bauchchirurgie differentialdiagnostisch von Interesse sein dürfte.

Aus der mir von Herrn Professor Dr. K rehl gutigst zur Verfugang gestellten Krankengeschichte entnehme ich als fur den vorliegenden Fall von Wichtigkeit, dass der 84 . Jahre alte Friedrich $W$. vor 10 Jahren eine Anschwellung der Beine von vierwöchentlicher Dauer gehabt, dem Alkohol fleissig zugesprochen und wegen vor kurzer Zeit aufgetretener Schwellung der Beine, des Scrotums und Abdomens im Juli 1901 die medicinische Klinik zu Greifswald aufgesucht hat.

Hier wurde ein mässiges Oedem an den Füssen und am Unterschenkel, starkes am Scrotum, der Unterseite des Penis gefunden, sowie ganz geringes Oedem an Rumpf, Armen und Händen. Der Thorax ist normal gebaut, Athmung oberflächlich und regelmässig, die rechte Seite scheint bei der Athmung etwas zurückzubleiben. Athemzüge 20 in der Minute. Lungengrenzen. V. R. U. oberer Rand der 5. Rippe, sehr wenig verschieblich.

H. R. U. beginnt eine Dampfung in Höhe des 6. Rippenwirbeldornfortsatzes, die nach unten hin fast absolut wird. H. L. U. ist in Höhe des XII. Brustwirbeldornfortsatzes, Verschieblichkeit der Lungen nicht festzustellen. Ueber den Spitzen bdsts. Vesiculärathmen. Unterhalb der Clavicula Athmen bdsts. gleichmässig scharf, von der 4. Rippe abwärts rechts vorn unten einige Rasselgeräusche H. u. r, abgeschwächtes Vesiculärathmen, mittelblasige Rasselgeräusche. H. u. l. gleicher Befund wie rechts.

Herzgegend scheint etwas vorgewölbt. Spitzenstoss leise fühlbar im 10. Intercostalraum, in der Mamillarlinie. Die Herzdämpfung nach beiden Seiten verbreitert. Am linken Sternalrand in Höhe der 4. Rippe ein diastolisches Geräusch, über den beiden anderen Ostien systolische Geräusche. Der II. Pulmonalton erscheint verstärkt, Puls unregelmässig klein, 60 in der Minute.

Abdomen etwas aufgetrieben, Appetit gut, Stuhlgang normal. An den Rachenorganen nichts Abnormes. Leber und Milz scheinen nicht vergrössert. Die seitlichen Partieen hängen etwas ab, Fluctuation vorhanden. Etwas uber Nabelhöhe $2 \mathrm{~cm}$ ausserhalb der Mamillarlinie deutliche Dämpfung. Verschieblichkeit aber nicht deutlich, pralle Consistenz. Gefühl der Fluctuation, Urinentleerung spontan. Urin entlält bei der Aufnahme ziemlich viel Eiweiss. Mikroskopisch zahlreiche granulirte und hyaline Cylinder.

18. Juli. Kein Albumen im Urin. 
26. Juli. Plötzlicher Exitus.

Diagnose: Marasmus senilia, Tumor in abdomine. Arteriosclerose. Hypertrophia cordis, Nephritis Pleuritis dextra.

Sectionsbefund 27. Juli 1901.

Mittelgrosser leidlich kräftig gebauter Mann mit spärlichem Fettpolster. Farbe der allgemeinen Körperhaut grauweiss, Musculatur in Todtenstarre, an den abhängigen Theilen livide Todtenflecke. Am Scrotum, an den oberen und unteren Extremitäton Oedeme. Abdomen leicht aufgetrieben. Bei der Eröffnung der Bauchhöhle fliesst hellgelbe klare Flussigkeit hervor. Die Gesammtmenge derselben und der frei in der Bauchhöhle befindlichen beträgt ungefähr $500 \mathrm{ccm}$. Das mässig, fett. reiche Netz uberlagert die linke Hălfte der vorderen Bauchwand, mit mit der es in grosser Ausdehnung fest verwachsen ist. Zahlreiche Darmschlingen sind unter einander und mit den Nachbarorganen durch, festfibröse Stränge z. Th. flächenhaft verbunden. Das Peritoneum im Allgemeinen verdickt, an den verschiedensten Stellen besonders mit der Leber fest verwachsen, theilweise ist es noch spiegelnd glatt und glänzend. In der Gegend des Processus vermiformis fibröse Stränge, derselbe ist verödet, in dickes schwieliges Narbengewebe eingebettet. Stand des Zwerchfells wegen umfangreicher Verwachsungen mit der Leber und Milz nicht genau zu bestimmen.

Das grosse Netz erscheint im Lebrigen mit dem Quercolon in normaler Verbindung, beide bilden mit der grossen Curvatur des Magens einen convex in die Bauchhöhle vorspringenden Bogen. Zwischen Magen und Leber wölbt sich eine grosse prall gefüllte Blase hervor, welche an mehreren Stellen, so nahe dem $\Lambda$ ufhängeband der Leber und links bis in die Gegend der Milz vorragend, hühnereigrosse Protuberanzen bildet, welche durch eine dünne fibröse Haut klaren wässerigen Inhalt durchschimmern lassen. Da es bei äusserer Betrachtung nicht sogleich klar wird, ob hier eine einfache oder multiloculäre Cyste vorliegt, so wird an einer Stelle eröffnet und der hellgelbe wässerig klare Inhalt in Menge von etwa $1200 \mathrm{ccm}$ ausgeschöpft. Hierbei zeigt sich, dass die Compression des Magens, durch welche derselbe wie eine Säbelscheide in einem nach unten convexen Bogen plattgedrückt erschien, durch eine Cyste herbeigeführt ist, welche zwischen Leber und Magen liegt. Längs der grossen Curvatur ist der Magen mit dem scharfen Rande der Leber in eine feste Verwachsung eingetreten, welche sich rechts auf das Duodenum fortsetzt, und nach links den Fundus des Magens betrifft, der mit dem linken Leberlappen und dem Zwerchfell fest adhärent geworden ist. Hierdurch ist ein abgeschlossener intraperitonealer Sack entstanden, welcher bei starker Ausdehnung als vordere Begrenzung die vordere Magenwand hat, die etwas abnorm gestellt ist, da die grosse Curvatur durch die Fixirung am scharfen Leberrande oben festgehalten wird. Unter der kleinen 
Curvatur spannt die Cyste das Ligamentum hepato-duodenale prall an, sodass man beim Eingehen mit dem Finger in die Bursa omentalis den untersten Abschnitt der abgekapselten Cyste hätte fühlen können. Ein Versuch dieser Art vor Eröffnung der Cyste führte deswegen zu keinem Resultat, da das Winslow'sche Loch durch feste Verwachsungen unzugänglich war. Nach oben und hinten bildet der Ueberzug der Leber, und zwar deren gesammte untere Fläche die Grenze, resp. Wand der Cyste, welche sich demnach als eine partielle abgesackte, mit klarem Inhalt gefüllte intraperitoneale peritonitische Exsudathöhle erweist. Die Protuberanzen sind einer stärkeren Vorwölbung zu verdanken, welche die an den genannten Stellen etwas dünnere Adhäsion durch den Cysteninhalt erfahren hat.

Das Herz ist doppelt so gross wie die Faust der Leiche, seine sämmtlichen Theile prall gefüllt mit Blut- und Speckgerinnsel. Pericard spiegelnd glatt und glänzend. Subpericardiales Fettgewebe reichlich entwickelt von strohgelber Farbe. Museulatur des r. Ventrikels $1 \mathrm{~cm}$ dick von lehmigbraunröthlicher Farbe. R. Ventrikel und Vorhof stark dilatirt. Unter dem intacten Endocard kleine Blutungen. Pulmonalklappen zart, intact.

Die bräunlichgelbliche Musculatur des linken Ventrikels misst $21 / 2 \mathrm{~cm}$. Das Endocard besonders an der Valvula mitralis, die am Septumansatz in Folge starker Kalkeinlagerung sehr derb ist, theilweise fibrös degenerirt. Unter dem Endocard auch lier flohstichartige kleine Blutungen. Sehnenfäden zart und dünn. Im Bulbus aortae Atheromatose L. Ventrikel 9,5:10,25 cm lang, Ostium aortae $8,5 \mathrm{~cm}$ weit. Linker Vorhof und Ventrikel ebenfalls dilatirt. In den Kranzarterien starke Arteriosklerose.

Der Ueberzug der linken Lunge ist fast in toto mit der Pleura costalis verwachsen, sodass beide eine dicke Schwarte bilden. Nur am Unterlappen findet sich zwischen beiden Pleurablättern im tiefsten äusseren Theile des linken Brustraums eine über gänseeigrosse cystische $\mathrm{Ab}$ kapselung klarer lymphatischer Flüssigkeit. Die Pleura pulmonalis und costalis, von bräunlich weisslicher Farbe, verdickt. Die Lunge fühlt sich iberall lufthaltig an, etwas verringerter Luftgehalt ist nur im untersten Theile des Unterlappens warznnehmen. Durchschnitt glatt, schwärzlichröthlich, Gewebssaft spärlich, blutig-schaumig klar. Die geröthete Bronchialschleimhaut ist mit geringem zähen glasigen Schleim belegt.

Die rechte Lunge ist grossentheils mit dem Rippenfell verwachsen, besonders im Oberlappen an der vorderen Seite, wo eine dicke Schwarte vorliegt. Nach Lostrennung derselben lassen sich aus dem rechten Brustfellraum etwa $300 \mathrm{ccm}$ leicht getrübter Flusssigkeit ausschöpfen. Die von Verwachsungen noch freie Pleura pulmon. der tbrigen Lunge ist theilweise verdickt und mit kleineren Blutungen durchsetzt. Zwischen den einzelnen drei Lappen spannen sich zartere und derbere fibröse Verwachsungsstränge aus. Im Mittellappen geringes Emphysem, im Uebrigen wird der untere scharfe Rand durch stärkere und feinere bindegewebige 
Verdickungen der Pleura etwas nach oben gewölbt, deformirt. Dasselbe Bild nur in ausgedehnterem Maasse bietet sich im Unterlappen, wo dessen freier Rand fast wurstförmig, wulstig nach oben rotirt ist. Die Pleura in diesem Bezirk ist stark verdickt, aber fast spiegelnd glatt. Der grösste Theil der rechten Lunge ist noch lufthaltig, nur die deformirten Abschnitte haben eine etwas derbere Consistenz. Der Durchschnitt der Lunge ist schwärzlich-röthlich, glatt; spärlicher blutig, schaumig, klarer Gewebssaft lässt sich abstreichen. Die Schleimhaut der Bronchien geröthet und mit glasig röthlichem Schleim bedeckt.

Die Milz ist iberall mit dem Zwerchfell verwacbsen, im Zustande chronischer Hyperplasie.

Beide Nieren bieten das Bild einer chronischen interstitiellen und katarrhalischen Nephritis, sind stark geschrumpft und von sehr derber Consistenz.

Die Leber ist nicht vergrössert, durch bindegewebige Stränge überall mit der vorderen Bauchwand und dem $Z$ werchfell, abgesehen von dem oben gegebenen Befund, verwachsen derb und von exquisit brauner Farbe mit deutlicher Acinuszeichnung.

Die ubrigen Bauchorgane zeigen nichts Besonderes.

Pathologisch-anatomische Diagnos:

Hyperplasia permagna et dilatatio ventriculi utriusque cordis. Myocarditis parenchymatosa. Pleuritis chronica dextra deformans. Synechiae pleurae sin. Hydrotharax. Ascites. Perisplenitis et Perihepatitis chronica fibrosa adhaesiva. Nephritis interstitialis et catarrhalis. Perityphlitis chronica fibrosa, Appendicitis chronica obliterans. Peritonitis chronica et partialiter incapsulata.

Im Vordergrunde des Interesses steht die zwischen Magen und Leber gelegene Cyste.

Die Gegend des Processus vermiformis ist äusserst schwielig verdickt, fibröse Verwachsungen sind hier vorhanden, wie überall in der Bauchhöhle. Ohne etwas in der Anamnese darüber zu erfahren, können wir annehmen, dass früher einmal eine Perityphlitis bestanden, die nach Durchbruch der Eitererreger aus dem Processus zu einer allgemeinen Peritonitis geführt hat, deren Endresultat wir jetzt vor uns sehen in den zahlreichen Verwachsungen der Dünndarmschlingen, in den Verwachsungen der Leber, in der von derbem, fibrösem Gewebe und verdicktem Peritoneum umgebenen Cyste zwischen Leber und Magen. Unzweifelhaft haben wir es hier mit einer chronischen abgekapselten Peritonitis zu thun. Durch die Verwachsungen der Leber und des Magens mit der vorderen Bauchwand ist ein Raum abgeschlossen worden, der vielleicht anfänglich kleiner, durch vermehrte Flüssigkeitsansammlung und vermehrte Flüssigkeitsaufnahme aus der mit Exsudat und Ascites erfüllten Bauchhöhle zu seiner jetzigen Grösse angewachsen, vollkommen abgekapselt ist, und nun einen hinter dem Magen liegenden Tumor vortäuscht. Vielleicht hat zur Entstehung 
dieses immerhin ungewöhnlich grossen Sackes eine geringe Gastroptose beigetragen.

Intra vitam war die Diagnose auf einen Tumor in abdomine gestellt worden, aus einer deutlichen Dämpfung $2 \mathrm{~cm}$ ausserhalb der Mammillarlinie etwas über Nabelhöhe.'

Von Tumoren können hier Geschwülste des Magens vorkommen, doch waren dafür hier keine Anhaltspunkte zu finden. In nächster Linie käme aber, da der Magen intact war und sich auch vor der Geschwulst liegend bei der Aufblähung erwiesen hatte, an dieser Stelle nur eine Pankreascyste in Betracht. „Für die Diagnose einer solchen ist der Sitz in der Gegend des Pankreas hinter dem Magen wichtig, ihre fluctuirende Beschaffenheit und der Mangel aller localen und allgemeinen Entzündungserscheinungen" (Tillmanns). Alle diese Symptome waren hier vorhanden, und man hätte nach Ausschliessung aller Möglichkeiten an eine abgekapselte Peritonitis an dieser Stelle zu denken, lag ausser dem Bereich der gewöhnlichen Annahmen - eben nur den Verdacht auf eine Pankreascyste haben können. Das Pankreas lag aber an normaler Stelle und war vollkommen unverändert.

Trotzdem ein solcher Fall sehr vereinzelt ist und äusserst selten vorkommen mag - ich habe einen gleichen in der Literatur nicht gefunden -, er ist ein Curiosum und verdient für die moderne Bauchchirurgie als Beitrag zur Differentialdiagnose der Pankreascysten angeführt zu werden.

\section{Literaturverzeichniss.}

I.

Bayer, Bedeutung des Fettgewebes für den Aufbau der lymphatischen Neubildungen. Zeitschr. f. Heilkunde. XII. 1891.

Birch-Hirschfeld, Lehrbuch der pathol. Anatomie. II.

Esmarch und Kuhlenkampff, Die elephantiastischen Formen. Hamburg 1885.

Heidenhain, Versuche und Fragen zur Lehre von der Lymphbildung. Archiv

f. Physiologie v. Pflüger. Bd. 29.

Klebs, Allgemeine patholog. Morphologie. Jena.

Kruse, Ueber das Chylangioma cavernosum. Virch. Arch. 125. Bd. 1891.

Küttner, Intermittirende Entzündung der Lymphangiome. Beiträge v. Bruns XVIII. 1897.

Landois, Lehrbuch der Physiologie. 1899.

Langhans, Lymphangiom der unteren Extremität. Virchow's Arch. 7j. Bd. 1875.

Lücke.

Lesser und Beneke, Lymphangioma tuberosum multiplex. Virchow's Archiv. 123. Bd. 1891.

v. Lesser, Lymphangioma diffusum multiplex, Zeitschr. f. Chirurgie. 34. Bd. 1893. Li on, Lympheysten des Ligament. uteri latum. Virchow's Archiv. 144. Bd. 1896. Menzel, Ein Fall von Angioma cavernosum. Inaug.-Diss. Greifswald. 1894. 
N ass e, Ueber Lymphangiome. v. Langenbeck's Archiv. 38. Bd. 1889.

Zur Nieden, Lymphangiektasie und Lymphorrhagie. Virchow's Arch. 90. Bd. 1882.

Reichel, Angeborenes Lymphangioma cysticum. Virchow's Archiv. 46.Bd. 1869. Ritsch l, Ueber Lymphangiome der quergestreiften Muskeln. Beiträge v. Bruns. XV. Roth, Retroperitoneales cystisches Lymphangioma. Inaug.-Diss. Zürich 1880.

Sachs, lymphangiome am Auge. Ziegler's Beiträge. V. 1889.

Sam ter, Ueber Lymphangiome der Mundhöhle. v.Langenbcck's Arch. 41. Bd. 1891. Schmidt, Beiträge zur Kenntniss der Lymphangiome. Archiv für Dermatologie. XXII. 1890.

Schultes, Diffuse Lymphangiombildung am Oberschenkel. I.-Diss. Freiburg 1894. Török, Lymphangioma circumscriptum. Lymphangioma capillare varicosum. Monatshefte f. praktische Dermatologie. II. Bd. XI.

Unna, Lehrbuch der spec. patholog. Anatomie. v. Orth. Lfg. 8 .

Virch ow, Die krankhaften Geschwülste. III.

Wegner, Ueber Lymphangiome. v. Langenbeck's Archiv. Bd. XX. 1877.

Weichselbaum, Chylangioma cavernosum d. Mesenteriums. Virchow's Archiv. 64. Bd. 1875.

Winiwarter, Ein Fall von angeborener Makroglossie, combinirt mit Hygroma cysticum colli congenitum. v. Langenbeck's Arch. Bd. XVI.

W un sch, Zur Casuistik der Lymphangiome am Thorax. Inaug.-Diss. Greifswald 1894.

II.

Killian, Eine grosse retroperitoneale Cyste mit chylusartigem Inhalt. Berliner klin. Wochenschrift. Nr. 25. 1886.

Lion, Ein Fall von Lympheyste des Ligamentum uteri latum. Beitrag zur Kenntniss von den abdominalen Lymphcysten. Virchow's Archiv. 144. Bd. 1896. (Ausgedehnteste Zusammenstellung mesenterieller Cysten.)

Na rath, Ueber retroperitoneale Lymphcysten. Archiv f. klin. Chirurgie. Bd. L. Winter, Zeitschrift für Geburtshilfe und Gynäkologie. Bd. XXXIII. 1895.

\section{III.}

Koblanek und Pforte, Hydronephrose mit chylusähnlichem Inhalt und eigenartiger Wand. (Literatur über ähnliche Fälle s. daselbst.) Virchow's Archiv. Bd. 161. 1900.

Tillmanns, Lehrbuch der speciellen Chirurgie. 